\title{
NACIONALISMOS EN PALESTINA DURANTE LA ERA OTOMANA Y EL MANDATO BRITÁNICO
}

\author{
José Antonio Rocamora Rocamora \\ Departamento de Humanidades Contemporáneas \\ Universidad de Alicante
}

\section{RESUMEN}

El conflicto entre árabes e israelíes hunde sus raíces en la aparición del nacionalismo. Antes del nacionalismo, las comunidades se definían por otros criterios, especialmente el religioso. La comunidad judía asentada en Palestina vivió en razonable armonía con sus vecinos árabes durante siglos. Cuando un sector de los judíos europeos elaboró un nacionalismo propio, el sionismo, y emprendió la tarea de construir un Estado judío en Palestina, esta convivencia quedó alterada. A su vez, la mayoría árabe planteó diversos proyectos nacionales, aunque la penetración del nacionalismo en esta comunidad fue más tardía y débil.

Palabras clave: Nacionalismo árabe, nacionalismo palestino, sionismo, Historia Contemporánea de Palestina.

\section{ABSTRACT}

The Arab and Israeli conflict has its roots in the appearance of the nationalism. Before the nationalism, the communities were defined by other criteria, especially the religious one. The Jewish community settled in Palestine, lived in an acceptable harmony with its Arab neighbours for centuries. When a group of European Jewish drew up its own nationalism, the Zionism, and undertook the task of building a Jewish state in Palestine, this coexistence was altered. At the same time, the Arab majority expressed several national projects, although the spreading of nationalism in this community was later and weaker. 
Key words: Arab Nationalism, Palestinian Nationalism, Zionism, Palestinian Contemporary History.

\section{INTRODUCCIÓN}

La reducida superficie de Palestina no impidió la proliferación de diversos nacionalismos. El carácter sagrado de su suelo para las tres grandes religiones monoteístas ${ }^{1}$ lejos de ser ajeno, fue fundamental para la definición del propio espacio palestino.

Antes de la aparición de la idea de comunidad nacional, las creencias religiosas solían ser el principal referente comunitario. En el siglo XIX Palestina ejerció un magnetismo sobre judíos y cristianos de Europa. Entre los primeros, puede señalarse el establecimiento de comunidades procedentes básicamente de Hungría caracterizadas por su carácter ultraortodoxo ${ }^{2}$. Entre los cristianos, fueron sentimientos religiosos los que animaron a los Templarios alemanes a asentarse en Jerusalén o en Haifa. Sin embargo, en la época en que se produjeron estas migraciones, Europa estaba viviendo un cambio que afectaría, tiempo después, a otras zonas del planeta: el surgimiento de la idea de nación como fuente primera y principal de identificación y de lealtad comunitaria.

La mayoría de estudios sobre el nacionalismo lo consideran un fenómeno moderno, aun admitiendo precedentes de la idea nacional. Algunos, como Anthony Smith, ponen más énfasis en ello y tanto él como Ernest Gellner señalron al pueblo judío a la hora de buscar los orígenes del nacionalismo ${ }^{3}$.

1. En fechas mucho más recientes, los baha'is se han sumado a la sacralización del espacio, ya que el fundador de esta confesión, Baha'u'llah, se estableció en Palestina en 1868, donde moriría en 1892.

2. Descendientes de esta comunidad se opusieron al sionismo y en la actualidad son el núcleo del grupo antisionista Naturei Karta. Entre quienes defendieron este retorno con motivación religiosa se hallaban David Reubeni, Joseph Nassi o Sabbati Zevi. Cristianos europeos defendieron esta idea, como James Bicheno, Palmerston, lord Ashley o el coronel Gawler, que conocía bien los procesos colonizadores por haber sido gobernador de Australia del Sur. En el Reino Unido se fundaron sociedades para favorecer el retorno, valorando la posibilidad de hacer de los judíos establecidos en Palestina una herramienta para expandir la influencia británica (Bichara Khader, Histoire de la Palestine, 3 vols. Tunis, Maison Tunisiene de l'Edition, 1976-1978. Vol. I, pp. 94-97).

3. Anthony D. Smith, La identidad nacional, Madrid, Trama, 1997, p. 45. Ernest Gellner, Nacionalismo, Barcelona, Destino, 1998, p. 50. Anthony D. Smith y otros investigadores se interesaron también por el caso judío como muestra del nacionalismo de diáspora, producido entre grupos que viven dispersos. 
De hecho ya Hans Kohn (1984), primer investigador del nacionalismo, habló de los antiguos griegos y judíos como pueblos poseedores de unas características nacionales, resaltando que algunas ideas nacionalistas -mesianismo, conciencia nacional histórica, concepto de pueblo escogido- tuvieron su origen en el pueblo judío. Los judíos ejemplificarían además la nación basada en el sentimiento de identidad diferenciada ${ }^{4}$. Kohn no fue un mero historiador del nacionalismo. Como Gellner, era un judío checo germanizado culturalmente y víctima del nazismo. Pero, a diferencia de Gellner, fue un sionista. En su Praga natal perteneció a la asociación juvenil Bar Kochba y entre 1924 y 1935 residió en Palestina, siendo miembro del grupo Brit Shalom, que defendía un binacionalismo. Rechazado por la mayoría sionista, Kohn se estableció en EE.UU., aunque afirmando siempre su identidad judía.

Meinecke estableció una división clásica entre nación política, vinculada a la voluntad y nación cultural, que suponía a la nación caracterizada por determinados rasgos naturales (lengua, raza, etc.). Sendas tendencias del nacionalismo evidenciaban esta dualidad, siendo 1870 -el año de la guerra franco-prusiana- considerado un punto de inflexión, a partir del cual el nacionalismo cultural iría cobrando fuerza. En dicha guerra, Francia cedió Alsacia y parte de Lorena al recién creado Imperio Alemán. Podemos rastrear en una familia alsaciana cómo el nacionalismo cultural desafiaría al hasta entonces dominante nacionalismo político. En 1870 Raphäel Dreyfus vivía en Mulhouse. Sintiéndose ciudadano francés, abandonó su ciudad natal y procuró que sus hijos no sirvieran en el ejército alemán. Raphäel Dreyfus era judío. Seguramente eso importaría poco a los nacionalistas políticos franceses, que verían en su comportamiento un modelo de patriotismo. Sus ideas debieron favorecer el ingreso de su hijo, Alfred Dreyfus, en el ejército francés, deseoso de ver su tierra reintegrada a la patria francesa. Es sobradamente conocido cómo este militar fue acusado por quienes, llevados por un nacionalismo cultural, cuestionaron su patriotismo por su origen judío.

\section{EL SIONISMO ANTES DEL MANDATO BRITÁNICO}

El problema de la familia Dreyfus era el de la dispersa comunidad judía, que era en todas partes una minoría diferenciada por su religión. Por lo tanto, durante siglos, la voluntad integradora requería abandonar la fe $e^{5}$. La difusión del

4. Hans Kohn, Historia del nacionalismo, Madrid, Fondo de Cultura Económica, 1984, pp. 38 y ss. Con frecuencia, nacionalistas relevantes como Renan conocieron bien la historia antigua de judíos y griegos.

5. Esta posibilidad siempre se mantuvo. De hecho, Hans Herzl, hijo del fundador del sionismo, se convirtió al cristianismo. 
nacionalismo parecía crear un nuevo escenario. Si la comunidad mayoritaria ya no se definía en términos religiosos, los judíos podían aspirar a ser unos ciudadanos más sin renunciar a su religión. Pero la realidad mostraba que tanto la comunidad mayoritaria como la minoritaria podían optar bien por la integración, bien por la segregación.

Siendo el nacionalismo un fenómeno novedoso, no es extraño que muchos europeos -fuesen judíos o no- permanecieran apegados a lealtades tradicionales (localismo, religión, etc.) y recibieran con hostilidad al nacionalismo. Entre los judíos que abrazaron la idea nacional habitualmente predominó el deseo de integrarse en sus sociedades. Theodor Herzl simpatizó en su juventud con el pangermanismo y mostró ulteriormente la impronta del nacionalismo alemán en su recurso a la propaganda mediante folletos, libros, himnos o banderas ${ }^{6}$. Herzl destacó la importancia del caso Dreyfus, al mostrar que de poco servía la voluntad integradora de los judíos si la mayoría se prefería segregación. Tal vez este impacto no fue inmediato ${ }^{7}$, pero condujo a la búsqueda de un camino propio. En una época de fulgurante ascenso del nacionalismo, parecía lógico pensar que si el judío era rechazado por otras naciones, debía crear la suya propia. Numerosas biografías -como la de Herzl- muestran que la evolución al nacionalismo judío se produjo solo después de percibir una discriminación. De ésta son prueba también hechos como la creación de una asociación gimnástica por judíos de lengua alemana de Estambul en 1895 ante el aumento del antisemitismo ${ }^{8}$.

Aunque Herzl, autor de El Estado judío (1896), es la figura capital del sionismo y fue sin duda un gran divulgador y organizador, no fue el primero en hablar de los judíos como una nacionalidad. Ya lo hicieron Najman Krojmal, o Graetz, que desarrolló una importante labor como historiador desvinculando

6. Joan B. Culla, La tierra más disputada. El sionismo, Israel y el conflicto de Palestina, Madrid, Alianza, 2005, p. 39.

7. Piterberg relaciona el influjo del caso Dreyfus sobre su pensamiento con su relación con el judío francés Bernard Lazare, a quien intentó atraer hacia el sionismo, sin conseguirlo, ya que Lazare se inclinaba por la integración (Gabriel Piterberg, The Returns of Zionism. Myths, Politics and Scholarship in Israel, London, Verso, 2008, pp. 8 y ss.). Otra muestra de las divergencias entre sionistas e integracionistas fue la oposición de la comunidad judía de Munich a que el primer Congreso Sionista se celebrase en su ciudad, temiendo que obstaculizase su voluntad integradora (Avi Shlaim, El muro de hierro. Israel y el mundo árabe, Granada, Almed, 2003, p. 37).

8. Las asociaciones gimnásticas propagaron el nacionalismo alemán. Gimnastas checos, rechazados por los germanos, crearon sus propias asociaciones, también nacionalistas. De la orientación nacionalista de sociedades gimnásticas judías dan fe la proliferación de denominaciones como Bar Kochba o Maccabi (Richard D. Mandell, Historia cultural del deporte, Barcelona, Bellaterra, 1986, pp. 182-184). 
la historia judía de la religión y afirmando su vínculo con Eretz Israel, la tierra de Israel. Moses Hess mostró en su obra Roma y Jerusalén. El último problema nacional (1862) un nacionalismo con rasgos mazzinianos, que combinaba lo particular con lo universal y esperaba el apoyo de Francia para crear un Estado judío en Palestina. Entre los pioneros del nacionalismo judío era frecuente encontrar una formación tradicional y una evolución posterior hacia el laicismo que pretendía la integración y que abandonaba la idea ante hechos como los pogromos de 1881. Es este el caso de Lilienblum, para quien los judíos podían optar entre mantener el statu quo, la asimilación y desaparición y -lo que consideraba preferible- un renacimiento nacional en Eretz Israel ${ }^{9}$.

Europa Oriental aportó los contingentes más numerosos para el sionismo y el asentamiento en Palestina, iniciado a fines del siglo XIX, debido a que la comunidad judía estaba en peores condiciones que en Europa Occidental. La cosmopolita ciudad rusa de Odessa, que proporcionó figuras a otros nacionalismos -como el griego Ypsilanti- fue un núcleo en el que se desarrollaron ideas nacionalistas judías. Con esta ciudad se relacionan, por ejemplo Smolenskin, Pinsker, Ajad Haam y Jabotinsky. La actividad de sociedades como Hovevei Zion o Kadima difundió ideas nacionalistas y favorables a la instalación en Palestina entre intelectuales judíos de Europa Oriental.

Una vez definido el pueblo, era necesario buscar una tierra para él. En una época caracterizada por la expansión colonial de países europeos o culturalmente europeizados, había muchos espacios habitados por pueblos «atrasados» susceptibles de considerarse aptos para la colonización por pueblos más «civilizados». Es algo que vemos acontecer en lugares tan dispares como América del Norte y Australia. Nos interesa mencionar algunos casos más relacionados con el objeto de nuestro estudio, como el de la Patagonia argentina, donde se establecieron desde 1865 galeses que buscaban preservar su identidad religiosa y nacional. Argentina sería el lugar escogido por el barón Hirsch para una colonización judía, creándose poblaciones como Moisés Ville hacia 1890. Otro modelo influyente fue el de la colonización francesa de Argelia. En él tuvo un destacado papel Edmont Rothschild, miembro de la rama francesa de esta familia. Aplicado en los primeros años de arribada de judíos a

9. Shlomo Avineri, La idea sionista. Notas sobre el pensamiento nacional judio, Jerusalén, La Semana Publicaciones, 1983, pp. 27, 51-58, 81-82 y 86. Las esperanzas de Hess sobre Napoleón III se revelarían infundadas. El emperador más bien percibió la importancia de un potencial nacionalismo árabe al que pudiera proteger. Llegó a pensar en una entidad árabe autónoma con capital en Damasco (Daniel Rivet, «Le rêve arabe de Napoleon III», en Charles-Robert Ageron (ed.), L'Algérie des Français, Paris, Éditions du Seuil, 1993, pp. 57-58). 
Palestina, fue abandonado más adelante, cuando se quiso suprimir de la mano de obra indígena, imprescindible en el modelo argelino. Un tercer modelo fue la colonización germana de Posnania, dentro del Imperio Alemán, pero poblada mayoritariamente por polacos. En él trabajaron judíos alemanes como Franz Oppenheimer y sobre todo Arthur Rupin. En éste hallamos -como en Max Nordau y tantos otros- una nueva muestra de la evolución recurrente: un judío intenta la integración en la sociedad en la que vive pero, al considerarla imposible, abraza el ideal sionista. Rupin renunció al judaísmo e intentó germanizar Posnania, pero no soportó el creciente antisemitismo. Combinó ideas socialistas con un profundo darwinismo social. Recibió una fuerte influencia de Chamberlain y cada vez se interesó más por la identidad racial ${ }^{10}$.

Argentina, Madagascar, Sudán, Uganda... fueron varias las opciones barajadas como destino para que una migración masiva construyese una patria. Con todo, Palestina era la opción preferible, porque permitía establecer un vínculo histórico con el territorio que resultaba especialmente valioso una vez que la secularización restaba valor a la religión como elemento aglutinador.

Los sionistas -comenzando por Herzl- desconocían Palestina. Herramientas ideológicas que en Europa se aplicaban en su contra, como el nacionalismo o el darwinismo social, serían empleados por ellos frente a los árabes, hacia los que mostraban un sentimiento de superioridad que, en el mejor de los casos, conducía a una actitud paternalista, tolerándolos como una minoría que debería agradecer el progreso introducido por los judíos. Con harta frecuencia tendieron a ignorar su existencia. Es lo que denunció Ajad Haam en un escrito de 1891, en el que habló de la densa población árabe -hecho ignorado por muchos sionistas- de Palestina y del potencial desarrollo en ella de un movimiento nacional. En 1907 Yitzhak Epstein insistió en que se había relegado una cuestión tan importante como las relaciones con los árabes ${ }^{11}$.

Con cierto atraso respecto a Europa, las comunidades judías del Imperio Otomano, en gran medida sefardíes, también experimentaron un proceso de secularización. Un ejemplo de ello fue Abraham Galante, que dirigió en El Cairo el periódico La Vara. Fue excomulgado por el Gran Rabino de Estambul y encabezó un grupo de judíos de Egipto que participó en el Segundo Congreso de Oposición al Imperio Otomano, celebrado en París en $1907^{12}$. En estos

10. Al morir en 1943, dejó inacabada una obra sobre la raza judía. Gabriel Piterberg, o. c., pp. 65 y $79-84$.

11. Avi Shlaim, o. c., pp. 35 y 38-39. Shlomo Avineri, o. c., pp. 140-142.

12. Yves Ternon, Les Arméniens. Histoire d’un génocide, Paris, Éditions du Seuil, 1996, p. 164-165. 
grupos se planteó también el dilema entre integración en un Estado moderno o adopción del nacionalismo judío.

En la medida que el sionismo relegaba la religión como elemento identificador, precisaba otros elementos que confiriesen una identidad. La lengua podía resultar adecuada, pero presentaba problemas. La dispersa población judía hablaba multitud de lenguas. Una posibilidad era asumir alguna de ellas, especialmente el yiddish, empleado por numerosos judíos de Europa Oriental y de uso común entre los inmigrados a Palestina. Pero era una lengua germánica y vinculada con el exilio. Otro tanto sucedía con el sefardí, hablado en una amplia zona que abarcaba el Norte de África y el Imperio Otomano e incluía a muchos judíos residentes en Palestina antes de la inmigración sionista. Era una lengua desconocida -y con frecuencia despreciada- por los sionistas, mayoritariamente de origen askenazí.

Se abrió camino el hebreo moderno, vinculado -aunque existan precedentes- a la figura de Ben Yehuda. Establecido en 1881 en Jaffa, pensaba que el núcleo de la nacionalidad era la lengua y secularizó una lengua empleada sólo para el culto, irritando a los ortodoxos. Sectores del sionismo, incluido el propio Herzl, estimaban que el uso del hebreo por el futuro Estado era inviable y entre 1913 y 1914 hubo una guerra lingüística para determinar la lengua de enseñanza en el Instituto Tecnológico de Haifa, imponiéndose los partidarios del hebreo sobre los del alemán. En muchos casos los padres aprendieron de sus hijos la que sería lengua nacional ${ }^{13}$.

El hebreo se empleó para integrar a los inmigrantes con los judíos sionistas y diferenciarlos de la población árabe. En 1910 Jacob Fichman se opuso a la introducción de palabras árabes, pese a ser una lengua semita, porque el árabe no tenía lugar en la psique judía. Además, su enseñanza permitió difundir entre los inmigrantes y sus hijos ideas nacionalistas (símbolos, héroes, historia o fiestas nacionales), propiciando la adopción de nombres hebreos, lo que constituía todo un rito de paso ${ }^{14}$.

A inicios del siglo XX el nacionalismo judío no era la opción preferida por la comunidad judía a nivel mundial. Eran muchos más los partidarios del statu quo -como comunidad diferenciada por la religión- o la integración, que en muchos casos optó por la emigración a Estados Unidos. Borochov, que estuvo influido por la corriente nacionalista conocida como austromarxismo,

13. Alain Dieckhoff, «Hebrew, the Language of National Daily Life», en Tony Judt, Denis Lacorne, Language, Nation and State. Identity Politics in a Multilingual Age, New York, Palgrave MacMillan, 2004, pp. 190-197.

14. Yasir Suleiman, A War of Words. Language and Conflict in the Middle East, Cambridge, Cambridge University Press, 2004, pp. 140-141 y 206. 
limitó la tendencia a la asimilación a la clase alta judía y pensaba que la emigración a América perpetuaría la proletarización de los judíos, concluyendo que la única solución era disponer de un territorio en Palestina ${ }^{15}$. No nos interesa tanto si sus ideas -que muestran la incipiente variedad de tendencias en el sionismo- eran acertadas, como destacar que los inmigrantes judíos en Palestina eran mayoritariamente personas que habían evolucionado en un sentido laico y nacionalista. Era una inmigración selectiva y fuertemente ideologizada, sin vínculos de lealtad con sus estados originarios ni con el Imperio Otomano. Esta lealtad se orientaba a una aún inexistente patria judía. Como la mayoría de inmigrantes conservó su ciudadanía originaria -siendo la rusa la más frecuente- muchos se vieron en el dilema al estallar la guerra de mantenerla -y ser tratados como enemigos- o tomar la otomana, como preferían Ben Yehuda y Ben Gurión ${ }^{16}$.

Durante la guerra, no todos los judíos de Palestina simpatizaron con los aliados. La Declaración Balfour (1917) amplió el apoyo de la comunidad judía a los británicos. Incluía el término hogar nacional, usado de modo ambiguo por el sionismo, aunque era evidente que su objetivo era la estatalidad ${ }^{17}$. Para Benny Morris el proyecto sionista sólo se podía realizar mediante una deliberada limpieza étnica que sólo por razones tácticas se detuvo temporalmente ${ }^{18}$.

\section{EL NACIONALISMO ENTRE LOS PALESTINOS BAJO EL IMPERIO OTOMANO}

La aparición del nacionalismo entre la población palestina no fue fácil. El núcleo de las tierras palestinas estaba en las tierras altas, menos desarrolladas económicamente que los núcleos de países vecinos, situados en zonas costeras o en llanuras del interior ${ }^{19}$. Esta ubicación estaba en consonancia con una estructura social y política más tradicional. Grandes terratenientes se situaban en la cúspide social y lideraban redes integradas por notables de diferente rango que ejercían su autoridad sobre el conjunto de la población. Dos grandes

15. Shlomo Avineri, o. c., pp. 161, 166 y 169.

16. Tom Segev, One Palestine, complete. Jews and Arabs under the British Mandate, Londres, Abacus, 2010, p. 16.

17. Una conocida muestra de esta ambigüedad se produjo al preguntar a Weizmann en la Conferencia de Paz de París por el significado de hogar nacional judío. Dijo que consistía en hacer Palestina tan judía como inglesa es Inglaterra, pero eludiendo incluso entonces hablar de Estado (Avi Shlaim, o. c., p. 43).

18. Cit. por Gabriel Piterberg, o. c., p. 29.

19. Rashid Khalidi, Palestinian Identitiy. The Construction of Modern National Conciousness, New York, Columbia University Press, 1997, p. 26. 
familias rivales destacaban: los Husseini y los Nashashibi, gozando los primeros de una posición más sólida.

Inicialmente no surgió un nacionalismo estrictamente palestino, sino proyectos que aspiraban a la unidad árabe o de la Gran Siria, ideas que solían entremezclarse y que rara vez se entendían como contrapuestas al Imperio Otomano. En 1880 solo algunos cristianos de Siria, Líbano y Palestina eran hostiles al imperio. Más en contacto con la cultura occidental, la minoría cristiana se sentía en condiciones de liderar la tarea modernizadora y en general, adoptó antes el nacionalismo, siendo la identificación religiosa sustituida por otra nacional ${ }^{20}$. Entonces se abrían dos posibilidades: la identificación en la ciudadanía compartida por los miembros del Estado o la búsqueda de otros elementos identitarios, siendo la lengua árabe el más visible.

Desde el poder hubo intentos para promover un nacionalismo estatal: el otomanismo. Algunas medidas reformistas para superar el sistema de millets, de base religiosa y establecer la igualdad de los ciudadanos en un Estado moderno. En 1869 hubo una reforma educativa, pero de efectos limitados, y que mantuvo la posición privilegiada del turco, incluso en tierras de lengua árabe. Las carencias en la educación elemental eran graves, prevaleciendo la enseñanza tradicional en mezquitas hasta 1908. Ya en los últimos años de dominio otomano, los esfuerzos para mejorar la enseñanza se incrementaron. Por otro lado, desde el siglo XIX, misioneros cristianos extranjeros fundaron centros como el católico College des Frères (1875) o el anglicano St. George's School (1899). No obstante, en 1914 unas tres cuartas partes de la población árabe en edad escolar no estaban escolarizadas ${ }^{21}$, aunque las tasas de escolarización de los cristianos eran netamente superiores a las de los musulmanes. Los judíos tuvieron cifras que se aproximaban a la plena escolarización. Las niñas estaban menos escolarizadas en todas las comunidades religiosas.

Numerosas biografías de miembros de la elite palestina muestran el interés de esta por la educación moderna, por ejemplo, la de Sa'id al-Husseini, que asistió a la escuela de la Alliance Israélite y llegaría a ser alcalde de Jerusalén y diputado por este distrito. Yusuf Diya' estudió primero en escuelas tradicionales de Jerusalén y amplió estudios en al-Azhar (El Cairo), para después acudir a un colegio protestante de Malta y al American Robert College de Estambul,

20. Cuando a inicios del XX cristianos ortodoxos de Jaffa propusieron a su líder Khalil asSakakini formar un partido cristiano, éste respondió que era ante todo árabe, debiendo crearse un partido nacional. (Bichara Khader, Histoire de la Palestine, 3 vols. Tunis, Maison Tunisiene de l'Edition, 1976-1978. Vol. II, pp. 19 y 57).

21. Rashid Khalidi, o. c., pp. 48 y 50. Basheer M. Nafi, Arabism, Islamism and the Palestine Question 1908-1941. A Political History, Reading, Ithaca, 1998, pp. 28-30, 64 y 66-68. 
aprendiendo francés, inglés y alemán. Su sobrino, Ruhi al-Khalidi, estudió en la Alliance Israélite de Jerusalén y en la escuela Salahiyya de los Padres Blancos, continuando sus estudios en Estambul y Francia.

La prensa empezó a desarrollarse con cabeceras como al-Quds en Jerusalén y al-Karmil en Haifa en 1908. Pero las tiradas eran cortas, la vida de los periódicos breve y no solían editarse diariamente. En 1912 Muhammad al-Maghiribi lamentaba la escasez de lectores y su inclinación por obras de baja calidad. El editor y fundador de al-Karmil, Najib Nassar, mostraba lealtad a Palestina y a la nación árabe, pero también fue un ardoroso opositor de la colonización sionista, de la que era buen conocedor. En el libro El sionismo: su historia, sus objetivos, su importancia (1911) habló de la base racial y de los objetivos políticos y nacionales del sionismo, poniendo énfasis en su capacidad organizativa -como las sociedades gimnásticas paramilitares- y su empleo de elementos simbólicos, como la bandera. Otro periódico relevante fue Filastin, de Jaffa, que estuvo próximo a los Nashashibi. Se enviaba gratuitamente a las localidades próximas para informar a los campesinos y empleó -como muestra su denominación- con frecuencia los términos «Palestina» $\mathrm{y}$ "palestino», aunque no fue el único en hacerlo. Uno de sus redactores era 'Isa al-'Isa, que estaba influenciado por Najib Nassar. La mayoría de periódicos palestinos fue abiertamente antisionista ${ }^{22}$.

Como el sionismo, el arabismo o panarabismo es un nacionalismo cultural. En algunos de sus defensores encontramos lugares comunes de este nacionalismo, como la imagen de una nación que había permanecido aletargada y era despertada por los nacionalistas. Piénsese en las obras Le réveil de la nation árabe de Azuri o The Arab Awakening de George Antonius. Con esto debe relacionarse el frecuente empleo del término ba'ath (resurgir), que denominaría después a un partido panarabista. Según los arabistas, la nación árabe no era una construcción, sino un hecho natural, incluso similar a un organismo. También se identifican aspectos que estuvieron presentes en el sionismo, como una fuerte admiración por Europa, visible en intelectuales como Salama Musa o Husri, así como en tendencias, percibiéndose en los años 30 interés por el nacionalismo autoritario. La idea de superación de la comunidad religiosa por la nacional, se halla, por ejemplo, en Amin al-Rihani.

No existía una separación marcada entre la aspiración a construir la Gran Siria y la unión árabe. Para una mayoría -aunque no para todos- la primera sería el núcleo de la segunda. Pero existían dudas sobre los límites de Siria.

22. Rashid Khalidi, o. c., pp. 54-58, 81-82 124-126. A. W. Kayyali, Histoire de la Palestine (1896-1940), Paris, L'Harmattan, 1985, pp. 26-27. 
Habitualmente incluía Palestina, Transjordania o Líbano, pero había más dudas sobre Irak y no faltaba quien -como Antun Sa'adah-incluyese Chipre ${ }^{23}$.

En su inicio, el nacionalismo árabe se difundió como algo compatible con la pertenencia al Imperio Otomano. El periodista de Alepo al-Kawakibi se contó entre los primeros arabistas que aspiraron a modernizar el Imperio Otomano, pidiendo su descentralización y el establecimiento de un califato árabe en La Meca. Ante el fracaso, sirios como Rashid Rida, al-Zahrawi, al-'Azm o al-Kawakibi se establecieron en El Cairo, huyendo de la opresión otomana. A fines del XIX Taihir al-Jaza'iri sería el más activo defensor de un reformismo arabo-islámico, creando en torno a él un club en Damasco que debatía sobre política, religión y cultura, aunque aún no era claramente nacionalista. Estuvo en contacto con oficiales de los Jóvenes Turcos destinados en Damasco. AlJaza'iri promovió un segundo club, integrado por jóvenes que habían cursado una enseñanza moderna. Se crearon varias sociedades secretas árabes, como al 'Ahd y al-'Arabiyya al-Fatat (Jóvenes Árabes), fundada por dos estudiantes de Estambul, uno de ellos el palestino al-Hadi. Posteriormente se implantó en círculos estudiantiles de Beirut, Damasco y París. Al-Fatat mantuvo -incluso durante la guerra- la lealtad al Imperio Otomano, al igual que el Partido de la Descentralización, fundado en 1912 por los exiliados de El Cairo ${ }^{24}$.

Tras la llegada al poder de los reformistas Jóvenes Turcos en 1908, Ruhi alKhalidi y su tío Sa'id al-Husseini se mostraron durante un debate parlamentario críticos con el sionismo, denunciando que su objetivo era crear un Estado judío en Siria. Nisim Mazliah, diputado judío de Izmir del partido gubernamental Comité de Unión y Progreso (CUP), defendió el sionismo, acusando a Ruhi al-Khalidi de falsear la realidad para atacar al gobierno. Cuando murió estaba preparando un estudio sobre el sionismo que -como su tío- conocía muy bien ${ }^{25}$.

23. La evolución de al-Rihani muestra además la conexión del nacionalismo árabe con Occidente. Nacido en Líbano, recibió en sus primeros años una educación francesa, teniendo una visión distorsionada de lo árabe. Se estableció en Estados Unidos, país que admiró profundamente y cuya ciudadanía adquirió. Solo recuperó el interés por lo árabe al leer a Carlyle. Propuso que los árabes imitasen la cohesión y eficacia propagandística de los sionistas (Carmen Ruiz Bravo, La controversia ideológica nacionalismo árabe/ nacionalismos locales. Oriente, 1918-1952, prólogo de Pedro Martínez Montavez, Madrid, Instituto Hispano-Árabe de Cultura, 1976, pp. 168-169, 207, 298, 365-366, 438-439 y 501).

24. Basheer M. Nafi, o. c., pp. 19-22, 25-28 y 35-38, 41-42.

25. Sa'id al-Husseini escribió en 1899 una carta a Herzl exponiendo que Palestina era una tierra densamente poblada y venerada por cristianos y musulmanes, concluyendo su mensaje con un «deje a Palestina en paz». Rashid Khalidi, o. c., pp. 69-70 y 75-78. Basheer M. Nafi, o. c., pp. 65-66. 
La existencia de otras identidades no excluía la presencia de cierta idea de palestinidad que se manifestó puntualmente. Por ejemplo, en 1908 se pidió que el Norte de Palestina, que pertenecía al vilayato de Beirut, se integrase en el sanjacado de Jerusalén. Poco antes, en el libro Le Réveil de la nation árabe, que circuló clandestinamente en Palestina, Najib Azuri mostró tener un claro concepto de la unidad palestina y del potencial impacto del sionismo. Aunque libanés, Azuri había trabajado como funcionario en el sanjacado de Jerusalén.

Entre 1910 y 1911 varios artículos periodísticos criticaron la compra de tierras por el Fondo Nacional Judío en al-Fula, donde hubo una fortaleza supuestamente construida por Saladino, produciéndose una importante movilización social ${ }^{26}$.

En 1908 se fundó en Estambul de la Sociedad de Hermandad Árabe-Otomana, en la que predominaron sirios. La sociedad se enfrentó a reformistas como al-'Azm y Rida -dispuestos a compatibilizar su nacionalismo árabe con el apoyo al gobierno del CUP- que aprobarían la disolución de la sociedad, acusada de connivencia en el intento golpista de 1909. A fines de ese año, tras desechar la creación de un partido, la oposición árabe al CUP se integró con la no árabe en el Partido Liberal Moderado. En Jerusalén tuvo el respaldo de los Husseini. En 1911 al-'Asabi, que había sido subgobernador de Nazaret, se quejó en el parlamento de la infrarrepresentación de los árabes y pidió una política antisionista.

Activistas de al-Fatat de París decidieron celebrar un Congreso Árabe, contactando para ello con el Partido de la Descentralización. El congreso se celebró en París del 17 al 23 de junio de 1913, asistiendo 25 personas que representaban tres líneas: arabistas de al-Fatat, cristianos profranceses del Líbano y descentralizadores moderados, leales aún al Imperio Otomano, al que el Congreso pediría una mayor descentralización. El Congreso Árabe recibió numerosos telegramas de la Gran Siria, pero también la condena de notables árabes o sectores islamistas o proturcos. Incluso Filastin o el más arabista alKarmil temieron que la separación del Imperio hiciera de Palestina una presa fácil para el sionismo ${ }^{27}$.

En los meses anteriores al estallido de la guerra, el antisionismo se intensificó y organizó. En enero de 1914 Ibry escribía a Rupin comentándole la existencia de organizaciones de jóvenes cristianos y musulmanes en Jaffa y Jerusalén creadas para oponerse al sionismo. Efectivamente, se crearon sociedades muy variadas, que a veces combinaban la oposición al sionismo con

26. Rashid Khalidi, o. c., 1997, pp. 27-31, 105-109.

27. Basheer M. Nafi, o. c., pp. 43-44. 
la aspiración al desarrollo económico y cultural. Najib Nassar influyó en la creación de dos sociedades arabistas y antisionistas. Se constituyeron incluso sociedades femeninas nacionalistas. Estudiantes palestinos de Al-Azhar, en El Cairo, fundaron la Sociedad de Resistencia a los Sionistas y la campaña antisionista de Filastin fue tan intensa que las autoridades otomanas suspendieron el periódico alegando que fomentaba tensiones interraciales. Filastin replicó que los sionistas no eran una raza, sino un grupo político, diferenciando entre sionistas y judíos, acusando a los primeros de romper la tradicional convivencia armónica con estos y de aspirar a controlar el país ${ }^{28}$.

En Palestina -aunque no sólo en Palestina- la existencia de lealtades políticas múltiples en los últimos años de dominio otomano era común. Para intelectuales palestinos como Diya' o Ruhi al-Khalidi, existía una compleja red de lealtades que incluían el ámbito local, pero también otros más amplios. Podían sentirse palestinos, sirios y árabes y al tiempo ser fieles al Imperio. Si bien lo último retrocedió durante la guerra ${ }^{29}$, el cónsul español en Jerusalén, Antonio de la Cierva, pudo testimoniar al inicio de la misma la fidelidad de los habitantes de Jerusalén al sultán ${ }^{30}$. Nafi también sostiene la existencia de lealtades múltiples y piensa que la fuerza de la idea árabe no podría medirse por el número de miembros de sus organizaciones, ya que los partidos, como otros elementos de la modernidad, eran novedosos, practicándose una política tradicional. No obstante, hubo esfuerzos por ampliar las bases sociales. Al-Fatat, por ejemplo, intentó en vísperas de la guerra integrar a jóvenes notables urbanos, jefes tribales, funcionarios y oficiales del ejército. Pero incluso entonces existía un consenso que daba prioridad a la defensa del Imperio sobre los derechos nacionales ${ }^{31}$.

La actitud dominante de los nacionalistas árabes hacia el sionismo fue la oposición, aunque hubo excepciones. Sectores del Partido de la Descentralización admiraban los conocimientos, recursos y capacidad para promover el progreso de los sionistas, llegando algunos exiliados en Egipto a ver en ellos posibles aliados en la lucha contra Estambul. Se abría la posibilidad de una comunidad que incluyera a todos los habitantes de tierras árabes. El judío palestino sionista Nassim Mullul, corresponsal del periódico al-Mukattam contactó con líderes del Partido de la Descentralización. En 1913 y 1914 hubo intentos de negociación por ambas partes. Los del judío Hochberg o del palestino al-Khalidi no progresaron. Los de Weizzman en El Cairo parecieron más

28. A. W. Kayyali, o. c., pp. 33-35, 40.

29. Rashid Khalidi, o. c., pp. 85, 157-158.

30. Tom Segev, o. c., p. 15.

31. Basheer M. Nafi, o. c., pp. 47-51, 54-55. 
esperanzadores. En 1913 el diario beirutí al-Ittihad al-'Uthmani defendió esta aproximación, coincidiendo con el Primer Congreso Árabe. Hochberg siguió los trabajos de este congreso, entrevistándose con sus principales dirigentes. Por cierto, aunque el congreso no se pronunció sobre la inmigración sionista, se opuso a la turca. Estos contactos fueron efímeros y no condujeron a ningún acuerdo. En 1913 Albert Antebi constataba que ningún notable palestino quería comprometer su posición favoreciendo abiertamente a los sionistas. Sin embargo, el II Congreso Sionista, celebrado ese año, apostó por un entendimiento con los árabes ${ }^{32}$.

\section{EL SIONISMO DURANTE EL MANDATO BRITÁNICO}

La ocupación de Palestina modificó radicalmente las expectativas del sionismo, que se vio reconocido como interlocutor por la potencia administradora. Se dieron pasos importantes hacia el autogobierno. Dispusieron -a diferencia de los palestinos- de auténticos partidos políticos o de instituciones financieras propias, como el Anglo-Palestine Bank o el Jewish National Found. A nivel local, la independencia municipal de Tel Aviv tras los disturbios de Jaffa en 1921 fue otra vía para el ejercicio del poder político. En la práctica, la Comisión Sionista funcionó como un gobierno que contaba con un centenar de empleados y más tarde esta función la desempeñó la Agencia Judía. En 1920 empezó a elegirse por sufragio universal un parlamento (Knesset), que a su vez nombraba un consejo permanente (Vaad Leumi). Ambos fueron reconocidos por los británicos en $1927^{33}$ En sanidad y justicia los judíos fueron prácticamente autónomos.

Los sionistas se opusieron a proyectos educativos inclusivos, como una escuela de formación agraria proyectada en 1921, que debía enseñar en árabe y hebreo en los cursos iniciales y en inglés en los superiores. Sus presiones llevaron a la creación de escuelas separadas. En 1923 los sionistas tenían un sistema educativo segregado, que fue aceptado por los británicos, que los creían capaces de mantenerlo y más cultos que la población árabe. En los años 30 el Vaad Leumi creó un departamento especializado en educación que el Reino Unido apenas supervisó. La mayoría de sus escuelas eran llamadas públicas y eran de tres tipos: ortodoxas, de capacitación agraria y nacionales. Al menos la mitad de alumnos asistía a las últimas, dividiéndose el resto entre las primeras en partes semejantes. La educación infantil fue una importante

32. Rashid Khalidi, o. c., p. 140. Basheer M. Nafi, o. c., pp. 59-62. Bichara Khader, o. c., vol. II, pp. 53-55.

33. Joan B. Culla, o. c., p. 103. 
herramienta de adoctrinamiento. Se utilizaba el hebreo y se inculcaba una historia de la tierra acorde con el sionismo. El director de la comisión educativa británica, Jerome Farrell, la comparó con la educación nazi. Las aulas no estaban masificadas pese a la elevada escolarización y la comunidad judía -dentro y fuera de Palestina- valoraba la importancia de la educación, destinando a ella un importante esfuerzo económico ${ }^{34}$. La fundación de la Universidad Hebrea sería el reflejo de un sólido sistema educativo, además de formar cuadros y proporcionar una imagen moderna del yishuv.

Durante el período británico la diversificación del nacionalismo judío se incrementó. Si bien ello podía favorecer tensiones internas, no es menos cierto que permitía a cualquier judío encontrar una opción nacionalista con la que identificarse. Quienes lo hicieron con las corrientes más autoritarias de moda en Europa, hallaron un líder en Jabotinsky. Su ideología se forjó en buena medida antes del Mandato, siendo especialmente relevante su estancia en Italia, influyéndole Marinetti o el nacionalismo italiano. Jabotinsky hablaba de la importancia de la disciplina, del líder, de los uniformes o de las masas, proponiendo una representación corporativa que sustituyese a la parlamentaria y daba más importancia a la raza que al territorio, el idioma o la religión, considerando al pueblo judío parte de la atmósfera cultural europea.

Un gran logro fue la integración en el nacionalismo de sectores apegados a la tradición. Aquí destacó Kook, primer gran rabino askenazí durante el Mandato, que se esforzó por lograr una síntesis del nacionalismo y la religión. Defendió la inmigración a Eretz Israel incluso de ateos que, inconscientemente, podían ser servidores de Dios y aceptó el uso del hebreo, que irritaba a los más tradicionalistas ${ }^{35}$. Sólo algunos judíos religiosos mantuvieron una tenaz oposición al sionismo, llegando el grupo Agudat Israel a denunciarlo en instancias internacionales, prefiriendo una Palestina árabe. Uno de sus miembros más destacados, Jacob Israel de Haan, a ser asesinado por un sionista a la salida de una sinagoga en 1924.

Weizmann puede considerarse un ejemplo de orientaciones muy arraigadas en el sionismo. Formuló en 1907 un sionismo sintético que superaba la disputa entre políticos (partidarios de la diplomacia) y prácticos (promotores de la inmigración). Era una estrategia oportunista, que -en el Mandato- podía aceptar a los árabes como socios de gobierno a través de un consejo elegido

34. Yasir Suleiman, o. c., p. 141.Tom Segev, o. c., pp. 390-392. Ilan Pappé, A History of Modern Palestine, Second Edition, New York, Cambridge University Press, 2006, pp. 88-89. 35. Shlomo Avineri, o. c., pp. 185-187, 191-192, 197-202, 206-207, 216 y 221-222. 
sobre la base de la paridad de las comunidades, pero que de cara al futuro, prefería el entendimiento directo con los británicos ${ }^{36}$.

Muchos sionistas mezclaron nacionalismo y socialismo. Fruto de su trabajo surgieron partidos socialistas sionistas como el marxista Ahdut Haavoda (1919), Hapoel Hatzair o el sindicato Histadrut (1920), que desarrolló tareas propias de un Estado.

Una curiosa muestra de la capacidad evolutiva del nacionalismo sionista fue la aparición a fines de los 30 e inicios de los 40 de la corriente canaanita, influida por nacionalismos orgánicos como el italiano, el alemán o el ruso. Afirmaba el origen nacional era anterior al monoteísmo y por eso Yonatan Ratosh distinguió en 1944 entre el hebreo -miembro del grupo nacional-y el judío - miembro de la comunidad religiosa- presentando estos términos como incompatibles. Llegaron a crear un Comité para la Consolidación de la Juventud Hebrea ${ }^{37}$. Obviamente esta muestra radical marcadamente historicista solo pudo captar a un puñado de intelectuales.

La consolidación del hebreo fue un gran éxito para los sionistas. En 1916 ya reivindicaron su cooficialidad, que lograrían -junto con el árabe y el inglés- bajo el Mandato. Lo emplearon en sellos y monedas para aprovechar el simbolismo de estos elementos y desarrollaron campañas para favorecer el aprendizaje del hebreo por los inmigrantes, apareciendo instituciones especializadas con un carácter marcadamente nacionalista y eslóganes como Judío, habla hebreo ${ }^{38}$.

Los sionistas fueron hábiles empleando mitos y conmemoraciones para aglutinar a la comunidad. Durante un tiempo, Joseph Trumpeldor fue el héroe nacional. Muerto en un combate con los árabes en Galilea en 1920, su mitificación permitía ensalzar la lucha por la patria ${ }^{39}$. El repertorio de actos para promocionar mitos nacionales fue muy amplio y abarcó desde el traslado de los muebles del despacho de Herzl a Jerusalén a la compra de la emblemática montaña de Masada. Algunos intentos sectoriales por consolidar mitos

36. Avi Shlaim, o. c., p. 44.

37. Gabriel Piterberg, o. c., pp. 66 y 108.

38. Yasir Suleiman, o. c., pp. 144-145. Tom Segev, o. c., p. 264.

39. Un Trumpeldor agonizante habría pronunciado -en hebreo- unas famosas últimas palabras: Es bueno morir por la patria. Sin embargo, como no sabía hebreo, parece que dijo una frase insultante en su ruso natal. Realmente, no importa tanto qué dijo como la influencia de la mítica frase. Yael Zerubavel, «The Historic, the Legendary, and the Incredible: Invented Tradition and Collective Memory in Israel», en John R. Gillis, editor, Commemorations.The Politics of National Identity, Princeton, Princeton University Press, 1996, pp. 106-108 y 113. 
fracasaron, como el de los revisionistas para hacer de Shlomo Ben-Yosef, terrorista del Irgún ejecutado por los británicos, un héroe nacional ${ }^{40}$.

\section{APROXIMACIONES FRACASADAS}

Durante siglos, los judíos asentados en Oriente Próximo convivieron con los árabes, siendo aceptable la armonía entre las comunidades. Eso explica que cuando Francia cedió el sanjacado de Alejandreta a Turquía, los judíos locales prefiriesen ir al exilio con sus vecinos árabes cristianos y musulmanes ${ }^{41}$. El sionismo deseaba alterar la sociedad tradicional. Por eso cabe preguntarse si tenía un proyecto de convivencia intercomunitaria para esa nueva sociedad.

Los intentos por buscar una convergencia con la mayoría árabe fueron escasos. Cuando Kalvarisky propuso en una asamblea la autonomía judía dentro de un reino árabe, con el hebreo como lengua cooficial, varias réplicas mostraron su oposición. Otra curiosa idea fue la del escritor y periodista Yehoshua Hatalmi, que deseaba fomentar los matrimonios mixtos. No es extraño que el sefardí Ya'akov Yehoshua escribiera a la Comisión Sionista hablando sobre las buenas relaciones existentes en el pasado y quejándose por el escaso peso de los sefardíes en la toma de decisiones. Dirigentes árabes también hablaron de esta buena relación antes del sionismo y el propio gobernador Storrs pensaba que los sefardíes preferían relacionarse con árabes antes que con sionistas ${ }^{42}$.

Hubo varios encuentros entre dirigentes sionistas y árabes, incluyendo al propio Faysal en 1919. A inicios del Mandato, el alcalde de Jerusalén, Musa Kazim al-Husseini expresó al sionista Ussishkin su malestar la incomprensión cultural y desdén con el que les trataban los sionistas. Ussishkin le pidió que las invitaciones para celebrar el primer aniversario de la entrada de los británicos se imprimieran en hebreo, por ser los judíos mayoría en Jerusalén. Al-Husseini contestó que muchos judíos entendían el árabe, pero no el hebreo. Ussishkin terminó diciendo que estaban dispuestos para la guerra, que causaría sufrimiento a ambas partes, pero especialmente a los árabes.

Ben Gurión se mostró muchas veces dispuesto a negociar y pactar. Pero entendía tales acuerdos como parte de una estrategia para consolidar unos avances y plantear posteriormente objetivos más ambiciosos. Así, cuando aceptó la partición del Plan Peel, confiaba en que nuevas arribadas de inmigrantes ampliarían el territorio judío. Este oportunismo estuvo presente en el

40. Tom Segev, o. c., pp. 300, 385 y 386.

41. Laurent Chabry y Annie Chabry, Politique et minorités au Proche-Orient. Les raisons d'une explosion, Paris, Maisonneuve\&Larose, 1987, p. 154.

42. Tom Segev, o. c., pp. 108, 113-116 y 408-410. 
encuentro que mantuvo en agosto de 1934 con el abogado Musa Alami, figura próxima al muftí, proponiéndole un autogobierno de Palestina con paridad entre árabes y judíos y la inclusión de Palestina en una federación árabe, de forma que aunque los judíos se convirtieran en mayoría en Palestina, serían una minoría a nivel federal, resaltando además la capacidad de los sionistas para promover el desarrollo. Alami rechazó la oferta, mostrándose dispuesto a aceptar un cantón autónomo en torno a Tel Aviv como parte de un país árabe y le prometió un encuentro con el muftí que no llegó a producirse.

Ben Gurión también habló con George Antonius, graduado -como Alanien Cambridge, o con al-Hadi, miembro del Istiqlal. Las conversaciones mostraron el abismo existente entre sionistas y árabes. Durante la Segunda Guerra Mundial, Ben Gurión endureció su actitud, oponiéndose a la creación de un Estado árabe en Palestina, alegando que disponían de enormes espacios. En este sentido se pronunciaron sionistas estadounidenses reunidos en Nueva York en 1942 con Weizmann y Ben Gurión ${ }^{43}$.

Jabotinsky, líder del revisionismo, manifestó en 1923 que el entendimiento con los árabes era imposible, porque no les convencerían con versiones edulcoradas del sionismo, siendo necesario prepararse para la lucha. Sus discrepancias con Ben Gurión no radicaban tanto en los objetivos finales como en la estrategia. Ben Gurión reconocería hacia 1936 el carácter nacionalista de la oposición árabe al sionismo y la inevitabilidad del conflicto ${ }^{44}$.

Existen indicios de que no toda la relación entre árabes y judíos desapareció en el conflicto. En lo económico, al finalizar el Mandato se habían creado en Palestina 1.400 sociedades comerciales mixtas. Las relaciones entre trabajadores palestinos y judíos fueron también intensas, existiendo proyectos para crear organizaciones conjuntas y secundando miembros de ambas comunidades algunas huelgas, como sucedería todavía en 1947. En la ciudad de Haifa la convivencia fue más pacífica que en Jerusalén o Jaffa.

Pero el objetivo sionista de establecer un Estado impidió un entendimiento. Los judíos solo conseguirían un lugar un lugar bajo el sol expulsando de él a otro pueblo. Por eso los sionistas recelaron de todo lo que pudiera implicar una confluencia con los árabes, como el discurso «anacional» del reducido Partido Comunista Palestino, la defensa de la cohabitación por la izquierda sionista de Poalei Zion, partidaria de la cohabitación o el grupo Brit Shalom, que contaba con intelectuales de Europa Central y que se mostraba poco

43. Avi Shlaim, o. c., p. 57. Efraim Karsh, Fabricating Israeli History. The «New Historians», Second Revised Edition, Londres, Frank Cass, 2000, pp. 48-49 y 59-60. Tom Segev, $o$. c., pp. 130, 375 y 378 .

44. Avi Shlaim, o. c., pp. 48-49 y 52-54. 
preocupado por la soberanía y partidario de una comunidad judía viviendo en un Estado unitario binacional. Del lado palestino, los notables también se opusieron también a la convergencia. Entre otros, Fawzi al-Husseini que se aproximó a Brit Shalom, fue asesinado por palestinos ${ }^{45}$.

\section{NACIONALISMO ENTRE LOS PALESTINOS DURANTE EL MANDATO BRITÁNICO}

Los británicos hicieron promesas para después de la guerra a sus aliados árabes. Basándose en ellas, una heterogénea coalición -que incluía a nacionalistas- aspiró a crear un Estado árabe en la Gran Siria, con Faysal como rey. La idea tuvo muchos adeptos palestinos y la comisión estadounidense de King y Crane registró en 1919 que más del 72\% de las peticiones de Siria (Palestina incluida) se oponían al programa sionista, obteniendo resultados más altos sólo dos peticiones a favor de la unidad e independencia de Siria ${ }^{46}$. Pero franceses y británicos acordaron un reparto de la zona como mandatos de la Sociedad de Naciones. La resistencia árabe sirvió de poco y en 1920 Faysal fue expulsado de Damasco por los franceses.

El sistema de mandatos fue menos ventajoso para los palestinos que para otros árabes, ya que no consiguieron una suficiente capacidad de autogobierno y debieron enfrentarse a los colonizadores y al sionismo.

El dominio británico no acabó con el dominio de la elite tradicional, que fue responsable del incremento de la organización política y cultural palestina en los primeros años del Mandato. También persistió el solapamiento de la identidad palestina con otras más amplias como la siria y la árabe.

No es extraño que los líderes aparecieran entre los Husseini, que tendieron a adoptar posiciones más proclives a la unidad árabe y la solidaridad islámica, y los Nashashibi, más pragmáticos, probritánicos y con objetivos estrictamente palestinos. Entre los segundos destacó Raghib al-Nashashibi, pero quien resultaría clave en el período fue Hajj Amin al-Husseini. Cuando los británicos sustituyeron en la alcaldía de Jerusalén a Musa al-Husseini por un Nashashibi, Amin al-Husseini huyó a Siria. Como tantos otros, había recibido una educación tanto tradicional religiosa como moderna. De vuelta a Jerusalén, se mostró dispuesto a cooperar con las autoridades coloniales. En 1920 murió el muftí y logró -mediante las presiones de sus partidarios musulmanes y cristianos- que los británicos le nombraran muftí. También presidió el Consejo Musulmán Supremo (CMS), creado a fines de 1921 y que

45. Ilan Pappé, o. c., pp. 111-116.

46. Bichara Khader, o. c., vol. II, p. 86.

Investigaciones geográficas, $n^{\circ} 54$ (2011) 
le proporcionó poder en sanidad, justicia o educación, permitiéndole reforzar su vasta red clientelar, pues el CMS era, tras el gobierno británico, el mayor empleador palestino. Consciente del cambio que para el sionismo implicaba la presencia británica, conectó con círculos árabe-islámicos, rentabilizando el simbolismo de Palestina. No obstante, hasta 1929 mostró escaso interés por la política ${ }^{47}$.

Rashid Khalidi apunta la existencia de cambios que condujeron a la aparición de un fuerte sentido de identificación con Palestina desde la Primera Guerra Mundial, mencionando la urbanización, la difusión de la prensa o la sacralización de la tierra para musulmanes y cristianos. El nacionalismo palestino no era una simple reacción al sionismo, ya que el nacionalismo es un fenómeno universal. Cuando el gobierno de Damasco cayó, Musa Kasin al-Husseini dijo que Siria del Sur había dejado de existir y que había que defender Palestina y Hajj Amin escribió en 1920 un artículo mostrando amor a Palestina, sin hacer referencias a ámbitos más amplios. En marzo de 1921 Filastin puso énfasis en una identidad palestina diferenciada de Siria ${ }^{48}$. Pero conviene relativizar el calado de estos cambios, ya que no desapareció la adhesión a identidades más amplias ni el control de la elite tradicional.

Numerosas sociedades palestinas se mostraron muy activas. Entre ellas se contaba la Asociación Musulmano-Cristiana (AMC) de Jaffa, fundada a fines de 1918 y -pese a ser inicialmente impulsada por los británicos- opuesta a la Declaración Balfour. Sociedades similares aparecieron en diversas ciudades. En 1919 se fundó al Muntada al'Adabi, dominado por los Nashashibi y al-Nadi al-'Arabi (Club Árabe) de los jóvenes Husseini y sus allegados. Ambas fueron antisionistas y arabistas. El Club Árabe estuvo vinculado a clubes similares de al-Fatat en Siria y de hecho solicitó la integración de Palestina en el mandato sirio, aspirando a que el jerife fuese proclamado califa. El primer periódico durante el Mandato, fue Suriyya al-Janubiyya (Siria del Sur), de gran influencia pese a su corta vida. Su denominación mostraba la vinculación entre las ideas de Palestina, Siria y Arabia. Para 1920 había unas 40 sociedades en Palestina con unos 300 miembros, algunos militando en varias sociedades, pero eran capaces de movilizar a muchas más personas. En los cafés de Jerusalén se hablaba de política nacional y en los pueblos, la gente se agolpaba en torno a los maestros cuando leían la prensa.

A inicios de 1919 la AMC organizó el Primer Congreso Árabe Palestino. Los británicos, al clasificar a sus 27 participantes, calificaron a 11 de

47. Basheer M. Nafi, o. c., pp. 71-72, 89-92.

48. Rashid Khalidi, o. c., pp. 20, 149-150, 154, 165 y 168 y 173. 
nacionalistas palestinos y a 12 de nacionalistas árabes. Se habló de Palestina como parte de Siria, proclamando lealtad al gobierno árabe de Damasco y decidiendo enviar un memorandum a la Conferencia de Paz en París contra la Declaración Balfour y las reivindicaciones sionistas. Pero seis delegados, destacando 'Arif al-Dajani -presidente de la AMC- y Ya'qub Farraj no firmaron un documento que hablaba de la unidad siria y pidieron un gobierno palestino autónomo, opción preferida por los británicos.

Los sionistas - pese a negar la existencia de una nación árabe en Palestinasiguieron con interés el desarrollo del nacionalismo árabe e incluso intentaron convencer a los líderes árabes de que no significaban un peligro.

Conocedores de la situación, los británicos no dialogaron con el entramado societario palestino, entendiéndose directamente con las grandes familias. Cuando Herbert Samuel, primer Alto Comisario, llegó a Jerusalén, se entrevistó con Amin al-Husseini, consiguiendo de él la promesa de usar la influencia de su familia para mantener la paz. La política palestina padeció interferencias británicas. Hemos comentado el nombramiento de Amin al-Husseini como muftí. Pero además, potenciaron la figura del muftí de Jerusalén como líder religioso de todo el territorio. Cuando crearon en 1920 un consejo consultivo, Storrs se dirigió a miembros de la elite para indicarles que optasen entre desarrollar una carrera administrativa a la sombra del poder colonial o mantener sus actividades nacionalistas. Esto surtió efecto, especialmente entre los más mayores. Miembros más jóvenes de las elites tradicionales y de las clases medias instruidas mantuvieron la agitación nacionalista ${ }^{49}$.

Un Ejecutivo Palestino Árabe (EPA) fue dirigido desde 1920 por Musa Kasin al-Husseini. La organización cometió muchos errores y no fue reconocida por los británicos -a diferencia de la Comisión Sionista- como órgano representativo de su comunidad, vio mermada su influencia. Cuando los británicos decidieron convocar elecciones para una asamblea representativa, los palestinos las boicotearon. Es cierto que los palestinos tenían motivos para estar molestos, pero no lo es menos que de este modo mantenían en su puesto a unos notables poco eficientes y enfrentados entre sí.

Aunque el Mandato implicó que se pusiera más énfasis en Palestina respecto a las identidades siria y árabe, persistió una compleja relación entre ellas que dificultó la consolidación de un nacionalismo puramente palestino. Así, por ejemplo, el periodista palestino al-Tahir, influido por el arabista Arslan, creó en El Cairo al acabar la guerra un Comité Palestino y publicó el periódico

49. Basheer M. Nafi, o. c., pp. 68-70. A. W. Kayyali, o. c., pp. 66-68. Rashid Khalidi, o. c., pp. 163-165. Tom Segev, o. c., pp. 106, 110, 116 y 128. 
al-Shuna. Al-Tamini era un dirigente palestino de al-Fatat, la organización arabista más influyente durante el gobierno de Faysal en Damasco. Concluido este, Amin al-Husseini, a petición del Istiqlal, formó un comité para apoyar la revuelta del Monte Druso contra los franceses. En 1921 el Partido de la Unión Siria organizó un congreso en Ginebra, asistiendo también miembros del Istiqlal, el Comité Palestino y el EPA, que se mostró reacio por ser más moderado e inclinado a un nacionalismo palestino. Se pidió la unión de Siria, Líbano y Palestina, el final de los mandatos y la anulación de la Declaración Balfour, creando un comité ejecutivo permanente, uno de cuyos vicepresidentes fue el palestino Hammad. Cuando los delegados del EPA informaron de las decisiones, Musa Kasim al-Husseini, que estaba negociando en Londres, se opuso. Además, las reuniones entre sionistas y nacionalistas árabes sirios en noviembre de 1921 y julio de 1922 fueron percibidas como una interferencia en asuntos palestinos ${ }^{50}$. En 1925 se celebró en El Cairo el Congreso SirioPalestino, que habló de la especificidad siria y propuso constituir un comité general árabe para coordinar la acción política en Siria, Palestina y Transjordania, solicitando a la Sociedad de Naciones su integración en un único mandato. También se planteó difundir propaganda contra la Declaración Balfour en Europa y América ${ }^{51}$.

En Palestina fueron diversas las muestras de sentimientos identitarios compartidos. Un artículo de marzo de 1920 en Suriyya al-Janubiyya decía que el establecimiento de la AMC en Gaza sería bueno para el nacionalismo palestino y el nacionalismo árabe. En octubre de 1921, un artículo en al-Sabah, sucesor del anterior periódico, relacionaba la defensa de la causa palestina con la causa árabe. O en 1923 Sabri Sharif 'Abd al-Hadi, profesor de geografía en Nablus, publicó La Geografía natural de Siria y Palestina ${ }^{52}$.

Los palestinos emprendieron acciones propagandísticas para cohesionar la sociedad y para buscar solidaridades externas. Las asociaciones musulmano-cristianas publicaron folletos en inglés para ganar simpatías extranjeras. En 1922 empezaron a desarrollar el movimiento escoutista, crearon una sociedad económica árabe y proyectaron fundar un banco nacional árabe. Notables palestinos promovieron manifestaciones, marchas masivas, obras teatrales y periódicos ${ }^{53}$. En ocasiones imitaron estrategias propagandísticas sionistas, con campañas de reforestación o para que los palestinos compraran pequeñas

50. Basheer M. Nafi, o. c., pp. 92-94, 140-142 y 148-152.

51. Michael Provence, The Great Syrian Revolt and the Rise of Arab Nationalism, Austin, University of Texas Press, 2005, p. 147.

52. Rashid Khalidi, o. c., pp. 169 y 172, 174.

53. A. W. Kayyali, o. c., pp. 123-124. Ilan Pappé, o. c., p. 82. 
banderas nacionales. En 1926 se publicaban una docena de periódicos árabes, pero persistía el problema de los escasos lectores. Los sionistas alentaron las discordias internas, por ejemplo, utilizando las listas de quienes les vendían tierras, que incluían a alcaldes, políticos, líderes religiosos, empresarios o miembros de las familias Nashashibi o Husseini, como el padre de $\mathrm{Amin}^{54}$.

El árabe no fue un elemento integrador nacional en la misma medida que el hebreo. Por un lado, no era exclusivamente palestino, favoreciendo más bien una identificación árabe. Por otro, sus hablantes experimentaban un sentimiento de seguridad lingüística que no propició un uso ideologizado similar al del hebreo. Entre los hechos más relevantes sobre la lengua, destaca la fundación de la Academia de la Lengua Árabe por George Antonius ${ }^{55}$.

Kayyali indica que entre 1924 y 1928 hubo un estancamiento político, caracterizado por enfrentamientos entre el Comité Ejecutivo Árabe y el más moderado y probritánico Comité Central Ejecutivo del Partido Nacional y por el incremento de las luchas entre Nashashibis y Husseinis para controlar el CMS, ya que muchos notables pensaban que el liderazgo de Hajj Amin era una amenaza para su poder. La lucha por el liderazgo de la comunidad palestina parecía dejar en segundo plano la lucha contra el sionsimo. Pero las acciones de protesta no desaparecieron, como la huelga general y las banderas negras izadas con ocasión de la visita de Balfour para inaugurar la Universidad Hebrea, publicando entonces Filastin una edición en inglés ${ }^{56}$.

Desde 1928 se reactivó el enfrentamiento con los sionistas por al-Buraq (Muro de las Lamentaciones). El CMS convocó una conferencia árabe-islámica en Jerusalén para debatir la cuestión, pero la mayoría de los 700 fueron palestinos $^{57}$. En 1930 Chaim Arlosoroff estimaba que en 15 o 20 años el nacionalismo árabe sería similar al sionista ${ }^{58}$, aunque seguramente sus temores no tenían suficiente base.

Los intentos en 1931 de organizar un congreso islámico en Jerusalén con un comité organizador que incluía a Amin al-Husseini o Abd al-'Aziz al-Tha'alibi- hallaron resistencia sionista y británica y de los Nashashibi en el interior y en el exterior de dirigentes árabes y turcos, preocupados por una posible restauración del califato. El congreso no creó órganos que le dieran continuidad y mostró que el problema palestino no era aún una cuestión internacional relevante. Durante el congreso, el abogado palestino al-Hadi-que

54. Tom Segev, o. c., pp. 272, 275 y 302.

55. Yasir Suleiman, o. c., pp. 206-207. Tom Segev, o. c., pp. 272, 275, 302 y 355.

56. A. W. Kayyali, o. c., pp. 141-149.

57. Basheer M. Nafi, o. c., pp. 94-95.

58. Tom Segev, o. c., p. 350. 
había sido secretario personal del rey Faysal- convocó una reunión de nacionalistas árabes, acordando celebrar un congreso árabe, siendo sus principales impulsores istiqlalistas sirios y palestinos. Amin al-Husseini -cuyo arabismo en ese momento era cuestionable- no asistió a la reunión. El comité organizador avanzó lentamente, elaborando una propuesta que hablaba de una confederación panárabe ${ }^{59}$.

Aunque en 1933 el Alto Comisario Wanchope, pensaba que en Palestina se estaba desarrollando un sentimiento nacional, creía que el único capaz de modificar la situación seguía siendo el muftí y que la oposición más fuerte a él era la de los Nashashibi, siendo débiles los grupos nacionalistas más militantes, como el Partido Istiqlal Árabe, reactivado en 1932. A partir de ese año se fundaron varios partidos que siguieron vertebrándose en torno a las familias dominantes y no en torno a ideologías. Así el Partido Árabe Palestino, más arabista y beligerante contra sionistas y británicos, fue liderado por Jawal alHusseini y el Partido de la Defensa Nacional, que contaba con muchos notables y alcaldes, lo dirigió Raghib al-Nashashibi. La mayoría de partidos -y así sería en los siguientes años- carecía de programa o estructura democrática. El propio Istiqlal, que era el más moderno, mostraba de elementos arcaizantes. Su líder, Al-Hadi, pertenecía a una familia de notables y sus medios para movilizar a las masas no difirieron de los demás partidos ${ }^{60}$.

Otros grupos más reducidos estuvieron más ideologizados. En 1933 se creó NAL, una organización clandestina ardientemente panarabista. Representaba a una generación joven, de clase media y educación occidental. En su comité ejecutivo estaba el palestino al-Miqladi. Otro militante palestino fue Wasif Kamal, que había estudiado en Beirut y Londres. El NAL se relacionó con el Istiqlal y otras organizaciones de Palestina, Líbano, Siria e Iraq, promoviendo una conferencia arabista en agosto de 1933. La conferencia reflejó las tendencias autoritarias y potenciadoras del Estado en boga en la época. Los activistas palestinos del NAL fueron el núcleo del Comité de Defensa Palestino, especialmente tras su reorganización en 1937. Ese año, un grupo de palestinos, sirios y libaneses fundó el clandestino Partido Nacionalista Árabe ${ }^{61}$.

59. Posteriormente los iraquíes cobraron protagonismo en la organización del congreso. Su rey Faysal propuso solucionar el problema sionista creando un Estado sirio-iraquí, en el cual los judíos serían una minoría más reducida. Británicos y sirios del Partido Nacional se opusieron. En 1937 también el príncipe egipcio Mohammad Alí aceptó un hogar judío en Palestina en un reino pansirio, que probablemente aspiraba a dirigir Basheer M. Nafi, o. c., pp. 110-123, 163-169 y 269.

60. A. W. Kayyali, o. c., pp. 197-203. Basheer M. Nafi, o. c., pp. 172. Bichara Khader, o. c., vol. II, pp. 138, 159-161.

61. Basheer M. Nafi, o. c., pp. 194-195, 212-214 y 351. 
Las fuertes tensiones en la sociedad palestina propiciaron la revuelta de 1936, tras fracasar en 1935 el levantamiento de al-Qassam, un sirio establecido en Palestina que mezclaba arabismo e islamismo. La revuelta contó con muchos apoyos. Fue acompañada por una huelga general de seis meses que obtuvo un amplio -aunque no total- seguimiento y no produjo el colapso económico. La elite, temiendo verse desbordada, creó el Alto Comité Árabe (ACA), presidido por Amin al-Husseini e integrado por todos los partidos políticos e incluso por los Nashashibi. El ACA intentó mantener una postura más moderada que los rebeldes para poder negociar con los británicos y captar simpatías de árabes y musulmanes fuera de Palestina, pero no formuló ningún tipo de programa ni superó las crónicas divisiones entre los clanes.

No todos los rebeldes eran palestinos -había, por ejemplo, muchos transjordanos- ni actuaron siempre movidos por ideales nacionalistas. No se dotaron de una organización eficaz y pronto se vieron combatidos por otros palestinos, concretamente partidarios de los Nashashibi. Ello propició que los rebeldes y sus simpatizantes otorgasen gran valor al hatta, frente al turbante, considerado propio de clases acomodadas y relacionado con los Nashashibi.

La revuelta se dirigió básicamente contra los británicos, pero causó víctimas también entre los judíos. Los mártires fueron aprovechados por el sionismo para mantener la cohesión del grupo. La revuelta culminó a mediados de 1939, llegando a estimar el comisario británico que podía calificarse «movimiento nacional» por las simpatías que despertaba ${ }^{62}$.

Durante la revuelta se redactó el proyecto de partición de 1937, que beneficiaba al rey Abdullah de Transjordania. La retirada de los Nashashibi y sus partidarios del ACA poco antes de su publicación fue sospechosa. Los británicos ilegalizaron el ACA y propusieron sustituir al muftí en la presidencia del CMS, huyendo Hajj Amin a Líbano.

En septiembre de 1937 se celebró el congreso de Bludan, en Transjordania, asistiendo 450 personas, en su mayoría sirios, libaneses, palestinos y transjordanos. Aunque algunos arabistas lo boicotearon, contó con miembros del NAL, el Club al-Muthanna, el Movimiento de Liberación Árabe y otros panarabistas radicales. Pretendían organizar un congreso de jóvenes panarabistas que incluyese miembros desde el Norte de África al Yemen y solicitaron a los británicos un gobierno para Palestina similar al existente en Egipto o Irak, amenazando en caso contrario con boicotear sus productos. También en 1937 se celebró un Congreso Parlamentario Mundial para la Defensa de Palestina en Egipto, asistiendo unas 2.000 personas. Jamal al-Husseini encabezó

62. Basheer M. Nafi, o. c., pp. 194-195, 208-209 y 259-260. Tom Segev, o. c., pp. 360-370.. 
la delegación palestina. Se afirmó que el sionismo era una amenaza también para Egipto y -a diferencia del Congreso de Bludan-, afectó tanto a la esfera oficial como a la popular ${ }^{63}$.

A medida que transcurría el tiempo, el panarabismo compitió con nacionalismos basados en las fronteras establecidas. Mientras el primero debía recurrir a un desarrollo teórico para justificar la construcción de un Estado inexistente, quienes se acomodaban a las fronteras podían ser más pragmáticos y plantearse directamente el acceso limitado al poder que les permitía el sistema de mandatos. Además, podían beneficiarse de soportes teóricos para sus nacionalismos como los aportes de las investigaciones arqueológicas en toda la zona del Creciente Fértil. Así, un nacionalismo libanés establecería vínculos con los antiguos fenicios, el iraquí con las civilizaciones de Mesopotamia, etc. Los panarabistas eran conscientes de la importancia de Palestina para su causa y del peligro de la amenaza sionista, sin embargo se ocuparon poco por Palestina, seguramente porque debían enfrentarse a otros nacionalismos en sus países. Son excepcionales los casos de al-Rihani o Bayham, que incluso fueron a Estados Unidos para defender la causa palestina ${ }^{64}$.

\section{LOS BRITÁNICOS}

La arribada británica a Palestina fue un eslabón más en una dilatada trayectoria imperialista que debe valorarse. En varias de sus colonias se asentaron colonos, en su mayoría británicos. Cuando el número era suficientemente elevado, la población de origen europeo accedía al autogobierno, quedando la población autóctona supeditada en todos los aspectos. Incluso en la vecina Irlanda, la mayoritaria población católica había sido relegada a una ciudadanía de segunda, controlando el poder político, económico y cultural la minoría protestante.

No debe extrañar que los británicos llegaran con ideas preconcebidas y considerasen a la minoría sionista como un grupo cualitativamente superior al autóctono y merecedor de un trato diferenciado. Establecieron una especie de paridad entre las comunidades que no se correspondía a la realidad

63. Basheer M. Nafi, o. c., pp. 250-255 y 280-289.

64. Olivier Carré, Le nationalisme arabe, Paris, Fayard, 1993, pp. 11-12, 16-17. Carmen Ruiz Bravo, o. c., pp. 103-104 y 235. El hecho de que el vecino Egipto no prestase mucha atención a Palestina debe relacionarse con el hecho de que fue el país que mostró mayor celo por su identidad nacional propia y diferenciada de la árabe. Véase Ahmed Abdalla, «The Egyptian national identity and pan-Arabism: variations and generations», en Roel Meijer (ed.), Cosmopolitanism, Identity and Authenticity in the Middle East Richmond, Curzon, 1999, pp. 171-181. 
demográfica. En 1925, aunque los árabes eran el 88\% de la población, sólo tenían el $60 \%$ de los puestos de servicio público y concretamente los musulmanes, que eran el $78 \%$, sólo el $29 \%^{65}$. Además, solían tener trabajos peor remunerados.

Con todo, no debe pensarse que tuvieran una posición monolítica respecto a Palestina. El ministro Edwin Montagu -de origen judío y primo de Herbert Samuel- se negó a considerar a los judíos como una nación, porque eso dificultaba la opción integradora que él y tantos judíos compartían. Pero hubo más reticencias, como las del general Chaiton, jefe político y administrativo de Allenby, opuesto a la Declaración Balfour y molesto por el trato de favor a los judíos. Otros, en cambio, mostraron simpatías por los sionistas y algunos, como Ronald Storrs, los vieron como una especie de lealistas del Ulster. No fueron pocos quienes establecieron la comparación con el conflicto irlandés, entre ellos Herbert Samuel y los muchos militares y policías británicos antes destinados en Irlanda. En cambio, los nacionalistas judíos simpatizaron con sus homólogos irlandeses ${ }^{66}$.

La política británica hacia los palestinos tendió a mantener las luchas entre clanes en lugar de a modernizar la sociedad y la economía, mientras la educación fue más bien descuidada, tanto por su coste económico como por sus posibles efectos políticos. Concretamente la enseñanza de la historia estuvo estrictamente vigilada para evitar pensamientos subversivos ${ }^{67}$.

En 1929 el Reino Unido sustituyó un sistema económico unitario por otro segregado. Como los judíos pagaban más impuestos, la división les favoreció. Se produjo además en un momento oportuno, ya que antes necesitaron a los británicos para complementar su exiguo presupuesto ${ }^{68}$.

Todavía en los años 30, el memorandum de Rendel, asumido por el gobierno del Reino Unido, negó la existencia de una nación árabe. En el país hubo detractores de la partición, como Herbert Samuel, que prefería una entidad judía -no un Estado- integrada en el ámbito árabe ${ }^{69}$.

65. Yezid Sayigh, Armed Struggle and the Search for State. The Palestinian National Movement, 1949-1993, Oxford, Oxford University Press, 1999, p. 5.

66. Tom Segev, o. c., pp. 47, 90-91 y 180 y 433.

67. Rashid Khalidi, o. c., p. 174.

68. Ilan Pappé, o. c., pp. 93-94. Si en 1922 la economía judía era el 19\% del Producto Interior Neto de Palestina, en 1931 era el 44\%. (Joan B. Culla, o. c., p. 101).

69. Basheer M. Nafi, o. c., pp. 180-181 y 296. 


\section{CONCLUSIONES}

El sionismo fue un nacionalismo desarrollado en miembros de la comunidad judía europea que experimentaron un proceso de modernización y se vieron frustrados en su intento de integración en la comunidad mayoritaria del Estado. No fue la opción más popular entre los judíos, pero sí para los arribados a Palestina desde fines del XIX.

El objetivo nacionalista judío fue construir un Estado propio en Palestina. Ello dificultó un entendimiento con la población árabe. No hubo un intento serio para integrarse, pese a que existía una comunidad judía viviendo en paz desde hacía siglos o que se podían buscar argumentos ideológicos como el semitismo común. Podrían incluso haberse planteado adoptar la lengua árabe y liderar un movimiento árabe. Pero el fracaso de anteriores experiencias de integración y el sentimiento de superioridad respecto a los árabes explican esta falta de voluntad. Por otro lado, relegada la religión, sin idioma ni Estado propio, el sionismo se habría disuelto en el arabismo.

Entre los éxitos del sionismo destacan sus logros propagandísticos, tanto en el exterior, como en el seno de la comunidad. Desarrollaron una amplia variedad de matices en su nacionalismo e integraron a sectores tradicionales, siendo equiparable por su extensión o diversificación a los nacionalismos europeos. El empleo del hebreo y la enseñanza fueron importantes elementos nacionalizadores. Esto fue posible porque pese a carecer de Estado propio, sí gozaron de amplia autonomía política y financiera.

Al trasplantarse este nacionalismo a Palestina, halló un medio menos modernizado en todos los aspectos. Por ello el nacionalismo llegó con más retraso y menor intensidad a la sociedad palestina, que no conoció un relevo en sus grupos dirigentes, poco interesados en promover cambios que cuestionaran su posición y enzarzados en luchas intestinas para controlar el poder.

Como en tierras vecinas, se desarrolló un nacionalismo partidario de la unión siria o árabe. Esto pudo favorecer una confusión y dispersión de esfuerzos, así como una percepción de menor peligro del sionismo, sin que en contrapartida proporcionase ayudas externas considerables a los palestinos.

En países vecinos, tras la Primera Guerra Mundial, se desarrollaron nacionalismos asociados a las fronteras establecidas, aprovechando las posibilidades de acceder a cierto autogobierno. Sin embargo, la política británica tendió a que palestinos y sionistas compartieran el poder. Esto no se amoldaba a la realidad demográfica, pero sí a su percepción de diferencias cualitativas entre las comunidades. Las autoridades coloniales no pusieron demasiado énfasis en la integración de las comunidades ni en la modernización de la comunidad árabe. Una estructura anticuada, errores de las elites, la escasa difusión del 
nacionalismo, el solapamiento de ideas nacionales y la política colonial, harían que los nacionalismos árabopalestinos presentasen al final del Mandato una menor potencia que el sionista.

\section{BIBLIOGRAFÍA}

ABDALLA, Ahmed. «The Egyptian national identity and pan-Arabism: variations and generations», en MEIJER, Roel (ed.). Cosmopolitanism, Identity and Authenticity in the Middle East, Richmond, Curzon, 1999, pp. 171-181.

AVINERI, Shlomo. La idea sionista. Notas sobre el pensamiento nacional judio, Jerusalén, La Semana Publicaciones, 1983.

CARRÉ, Olivier. Le nationalisme arabe, Paris, Fayard, 1993.

Chabry, Laurent; Chabry, Annie. Politique et minorités au Proche-Orient. Les raisons d'une explosion, Paris, Maisonneuve\&Larose, 1987.

Culla, Joan B. La tierra más disputada. El sionismo, Israel y el conflicto de Palestina, Madrid, Alianza, 2005.

DIECKHOFF, Alain. «Hebrew, the Language of National Daily Life», en JUDT, Tony; LACORNE, Denis. Language, Nation and State. Identity Politics in a Multilingual Age, New York, Palgrave MacMillan, 2004, pp. 187-199.

GELLNER, Ernest. Nacionalismo, Barcelona, Destino, 1998.

KARSH, Efraim. Fabricating Israeli History. The «New Historians», Second Revised Edition, London, Frank Cass, 2000.

KaYYALI, A. W. Histoire de la Palestine (1896-1940), Paris, L'Harmattan, 1985.

KHADER, Bichara. Histoire de la Palestine, 3 vols., Tunis, Maison Tunisiene de l'Edition, 1976-1978.

Khalidi, Rashid. Palestinian Identitiy. The Construction of Modern National Conciousness, New York, Columbia University Press, 1997.

KoHN, Hans. Historia del nacionalismo, Fondo de Cultura Económica, Madrid, 1984.

MANDELL, Richard D. Historia cultural del deporte, Barcelona, Bellaterra, 1986.

NAFI, Basheer M. Arabism, Islamism and the Palestine Question 1908-1941. A Political History, Reading, Ithaca, 1998.

PAPPÉ, Ilan. A History of Modern Palestine, Second Edition, New York, Cambridge University Press, 2006.

PiterberG, Gabriel. The Returns of Zionism. Myths, Politics and Scholarship in Israel, London, Verso, 2008.

ProvenCE, Michael. The Great Syrian Revolt and the Rise of Arab Nationalism, Austin, University of Texas Press, 2005.

RIVET, Daniel.»Le rêve arabe de Napoleon III», en AGERON, Charles-Robert (ed.). L'Algérie des Français, Paris, Éditions du Seuil, 1993. 
RUIZ BRAVO, Carmen. La controversia ideológica nacionalismo árabe/ nacionalismos locales. Oriente, 1918-1952, prólogo de Pedro Martínez Montavez, Madrid, Instituto Hispano-Árabe de Cultura, 1976.

SAYIGH, Yezid. Armed Struggle and the Search for State. The Palestinian National Movement, 1949-1993, Oxford, Oxford University Press, 1999.

SEgEV, Tom. One Palestine, complete. Jews and Arabs under the British Mandate, London, Abacus, 2010.

Shlaim, Avi. El muro de hierro. Israel y el mundo árabe, Granada, Almed, 2003.

SMITH, Anthony D. La identidad nacional, Trama, Madrid, 1997.

Suleiman, Yasir. A War of Words. Language and Conflict in the Middle East, Cambridge, Cambridge University Press, 2004.

Ternon, Yves. Les Arméniens. Histoire d’un génocide, Paris, Éditions du Seuil, 1996.

ZERUBAVEL, Yael. «The Historic, the Legendary, and the Incredible: Invented Tradition and Collective Memory in Israel», en GILLIS, John R. (ed.). Commemorations. The Politics of National Identity, Princeton, Princeton University Press, 1996, pp. 105-123. 